\title{
Coating of Device with Immunologic Reagents
}

National Cancer Institute

\section{Source}

National Cancer Institute. Coating of Device with Immunologic Reagents. NCI

Thesaurus. Code C112967.

A procedure used to immobilize antigens or immunoglobulins on a device. 